\title{
MAGNET POWER SUPPLY SYSTEM FOR KEK B-FACTORY
}

\author{
Tadashi Kubo, Masato Yoshida \\ High Energy Accelerator Research Organization \\ Oho , Tsukuba-Shi , Ibaraki-Ken , 305 , Japan
}

\section{Abstract}

A number of magnet power supplies have to be newly prepared for KEK B-Factory accelerator except for a small number of power supplies recycled from TRISTAN. High stability and low long term drift of magnet current must be guaranteed for these new power supplies from the requirement of accelerator design. Many R\&D works have been put into practice from two years ago. Finally the type of power supplies with small and medium power has been decided to be switch mode.

\section{INTRODUCTION}

Power supplies for KEKB-Factory will be installed in 4 small and 4 large existing power supply stations used for TRISTAN. For R\&D we have manufactured unipolar $20 \mathrm{~kW}$ and bipolar $300 \mathrm{~W}$ switch mode power supplies. Many measurements have been carried out as to these power supplies. A lot of useful data have been obtained.

We have designed new power supply system being based on these R\&D works. Other construction works for power supply system have been going well in parallel at present. The companies that manufacture power supplies and other electronic parts on this year will be fixed on this May end. The outline of design concept and configuration etc. of the magnet power supply system for KEK BFactory will be described in this paper.

\section{SPECIFICATION OF POWER SUPPLIES}

Table 1. shows required specifications of magnet current and magnetic field ripple content inside $\mathrm{Cu}$ vacuum chamber.

$\begin{array}{llc}\begin{array}{l}\text { Power Supplies } \\ \text { for }\end{array} & \begin{array}{l}\text { Current Stability } \\ \text { (P-P) }\end{array} & \begin{array}{c}\text { Magnetic Field } \\ \text { Ripple Content(P-P) }\end{array} \\ \begin{array}{llc}\text { Superconducting } \\ \text { Quadrupole Mag. }\end{array} & 1 \times 10^{-4} / \text { year } & 1 \times 10^{-5} \\ \text { Quadrupole Mag. } & 1 \times 10^{-4} / \text { year } & 1 \times 10^{-5} \\ \text { Bending Mag } & 1 \times 10^{-4} / \text { year } & 1 \times 10^{-5} \\ \text { Sextupole Mag. } & 5 \times 10^{-4} / \text { year } & 5 \times 10^{-4} \\ \text { Steering Mag. } & 5 \times 10^{-4} / \text { year } & 5 \times 10^{-5}\end{array}$

Table 1. Required Specification for Magnet Current and Magnetic Field Ripple Content (P-P)
Small value of long term current stability has been adopted to guarantee the stable accelerator operation through the year. But this requirement is very severe for designing a hardware block diagram of a current control of power supply, because temperature change from winter to summer is about 40 degrees(Centigrade) in KEK.

Table 2. shows the rough parameters of power supplies estimated from lattice design, magnet resistance and voltage drop of the DC cable.

\begin{tabular}{|c|c|c|c|c|}
\hline $\begin{array}{l}\text { Magnet } \\
\text { Type }\end{array}$ & $\begin{array}{l}\text { Current } \\
\text { (A) }\end{array}$ & $\begin{array}{l}\text { Voltage } \\
\text { (V) }\end{array}$ & $\begin{array}{l}\text { Number } \\
\text { of Units }\end{array}$ & $\begin{array}{l}\text { Total } \\
\text { Unit }\end{array}$ \\
\hline \multirow[t]{6}{*}{ LER Dipole } & 1250 & $30-800$ & 4 & \\
\hline & 1000 & 110 & 3 & \\
\hline & 800 & $30-110$ & 7 & \\
\hline & 600 & 50 & 2 & \\
\hline & 500 & $20-70$ & 4 & \\
\hline & 5 & 10 & 3 & \\
\hline Wiggler & 1000 & 750 & 4 & 27 \\
\hline \multirow[t]{4}{*}{ Quadrupole } & 800 & $20-40$ & 2 & \\
\hline & 500 & $20-130$ & 109 & \\
\hline & 350 & $350-600$ & 7 & \\
\hline & 200 & $30-40$ & 8 & 126 \\
\hline Sextupole & 425 & $40-60$ & 54 & 54 \\
\hline \multirow{2}{*}{ Steering } & 10 & 50 & 58 & \\
\hline & 5 & $45-65$ & 860 & 918 \\
\hline \multirow[t]{3}{*}{ HER Dipole } & 840 & $20-600$ & 5 & \\
\hline & 500 & $10-20$ & 2 & \\
\hline & 10 & $10-70$ & 13 & 20 \\
\hline \multirow[t]{7}{*}{ Quadrupole } & 3500 & 60 & 1 & \\
\hline & 1600 & 60 & 1 & \\
\hline & 800 & 50 & 1 & \\
\hline & 600 & $20-450$ & 24 & \\
\hline & 500 & $10-1000$ & 83 & \\
\hline & 300 & 60 & 1 & \\
\hline & 200 & $30-40$ & 12 & 123 \\
\hline Sextupole & 425 & $40-80$ & 52 & 52 \\
\hline \multirow[t]{2}{*}{ Steering } & 10 & 50 & 41 & \\
\hline & 5 & $60-100$ & 831 & 872 \\
\hline \multicolumn{5}{|l|}{$\begin{array}{l}\text { Colliding Point } \\
\text { (Superconducting) }\end{array}$} \\
\hline Quadrupole & 3500 & 15 & 1 & \\
\hline Solenoid & 650 & 30 & 2 & \\
\hline Steering & 50 & 20 & 6 & \\
\hline
\end{tabular}

Table 2. List of magnet power supplies prepared for KEK B-Factory. 


\section{R\&D WORKS}

Various investigations have been carried out to satisfy the performances given in the specifications. The performance of power supply will be under the control of the performance of DAC, Error Amp., Shunt Resistor or Burden Resister of DCCT.

\subsection{Room Condition of the Power Supply Installation Area}

Room temperature of existing 8 power supply stations varies remarkably through the year, because the power supply stations have not air-conditioner. But it will be possible to keep the room temperature in the range of 10 to 40 degrees through the year by on/off control of ventilation fan [1].

\subsection{Electronic Parts}

All magnet current data set through control network are 16 bits, and are converted into analogue reference by DAC in the power supply. As a result of measurements, the temperature coefficients of DACs of a few companies proved to be below $5 \mathrm{ppm} /$ degree. However, except for steering magnet power supply temperature control of DAC will be necessary to satisfy the performance of power supply.

The measured temperature coefficients of a few types of operational amplifier proved to be below $0.1 \mathrm{ppm} /$ degree. These data will be enough to satisfy the performance of power supply.

Steering magnet power supply will be kept in natural room temperature to reduce the production cost. Therefore, the shunt resistor must have low temperature coefficient. Fortunately from many kinds of measurements it seems that it is possible to get such resistors from a few companies.

DCCT will be used for comparatively high current power supplies such as bending, quadrupole and sextupole magnet power supplies. Burden resistor has a function of converting a current signal of DCCT to a voltage signal. Measured temperature coefficient of typical burden resistors have been below $5 \mathrm{ppm} /$ degree. In this case temperature control of burden resister will be necessary.

\section{$3.3 R \& D$ of Power Supply}

R\&D of the power supply started from two years ago. Three companies joined to fabricate both unipolar $20 \mathrm{~kW}$ and bipolar $300 \mathrm{~W}$ switch mode power supplies. To realize the specification the control circuit including DAC, error amplifier and burden resistor for DCCT has been separated from hardware power unit and installed in air-conditioned room. This was a first plan of the power supply configuration of KEK B-Factory. Detail discussion has been made in the report [1]. Table 3. and Table 4. show the measured performances of the R\&D power supplies respectively.

\section{Company \\ Current Stability \\ (P-P) \\ Current Ripple \\ Content(P-P)}
A $\quad 40 \mathrm{ppm} / 89 \mathrm{~h}$
B $\quad 110 \mathrm{ppm} / 65 \mathrm{~h}$
$14.8 \mathrm{ppm}(5.9 \mathrm{~Hz})$
$102 \mathrm{ppm} / 43 \mathrm{~h}$
$5.1 \mathrm{ppm}(50 \mathrm{~Hz})$
$20.8 \mathrm{ppm}(50 \mathrm{~Hz})$
Load : $20 \mathrm{mH}, \quad 0.0755 \mathrm{ohm}$

Table 3. Measured Data of $20 \mathrm{~kW}(40 \mathrm{~V}, 500 \mathrm{~A})$ Power Supplies

$\begin{array}{lcc}\text { Company } & \begin{array}{c}\text { Current Stability } \\ (\mathrm{P}-\mathrm{P})\end{array} & \begin{array}{c}\text { Current Ripple } \\ \text { Content(P-P) }\end{array} \\ \mathrm{A} & 250 \mathrm{ppm} / 89 \mathrm{~h} & 1.2 \mathrm{ppm}(50 \mathrm{~Hz}) \\ \mathrm{C} & 10 \mathrm{ppm} / 69 \mathrm{~h} & 50 \mathrm{ppm}(50 \mathrm{~Hz}) \\ & \text { Load : } & 3.4 \mathrm{H}, \quad 8 \mathrm{ohm}\end{array}$

Table 4. Measured Data of 300W(60V,5A) ,Bipolar Power Supplies

It proved to be that to satisfy the required specifications have not been easy, but will be in our hands before long when the mass production of power supply starts on this fiscal year.

\section{DESIGN OF TOTAL POWER SUPPLY SYSTEM}

The estimation of R\&D power supplies have finished on this March end. The size of power supplies has been reduced remarkably in comparison with usual SCR + Transistor Dropper type power supply. Consequently, all power supplies for KEK B-Factory can be installed in existing power supply stations.

Figure: 1 shows a final configuration of the power supply system. The delicate electronic parts in control circuit will be temperature controlled by putting Peltie semiconductor on the cooling fin and will be assembled in power supply hardware unit in stead of separating. Figure: 2 shows a block diagram of temperature compensator.

\section{SCHEDULE}

All the power supplies will be manufactured within two years from this fiscal year. The manufacturers that product the power supplies on this year will be fixed on this May end. The wiring of power cable will be finished on this July end. Current monitor system and sequence controller will be ordered on this May end. Almost all of hardware devices except for the remaining power supplies will be installed up to the end of this fiscal year.

The actual adjustment of the power supply system from a point of view of both hardware and software systems will start from the beginning of next fiscal year. The preparation works for accelerator operation will be completed up to the end of September of next fiscal year. 


\section{CONCLUSION}

The design of power supply system started from three and a half years ago and the varieties of R\&D works started from two years ago. The final design of the power supply system has been greatly indebted to these R\&D works.

\section{REFERENCE}

[1] Ta. Kubo et al.,’Design of Magnet Power Supplies for KEKB Accelerator",Proc. of the 10th Symp. on Acc. Sci. and Tcch.,118(1995)

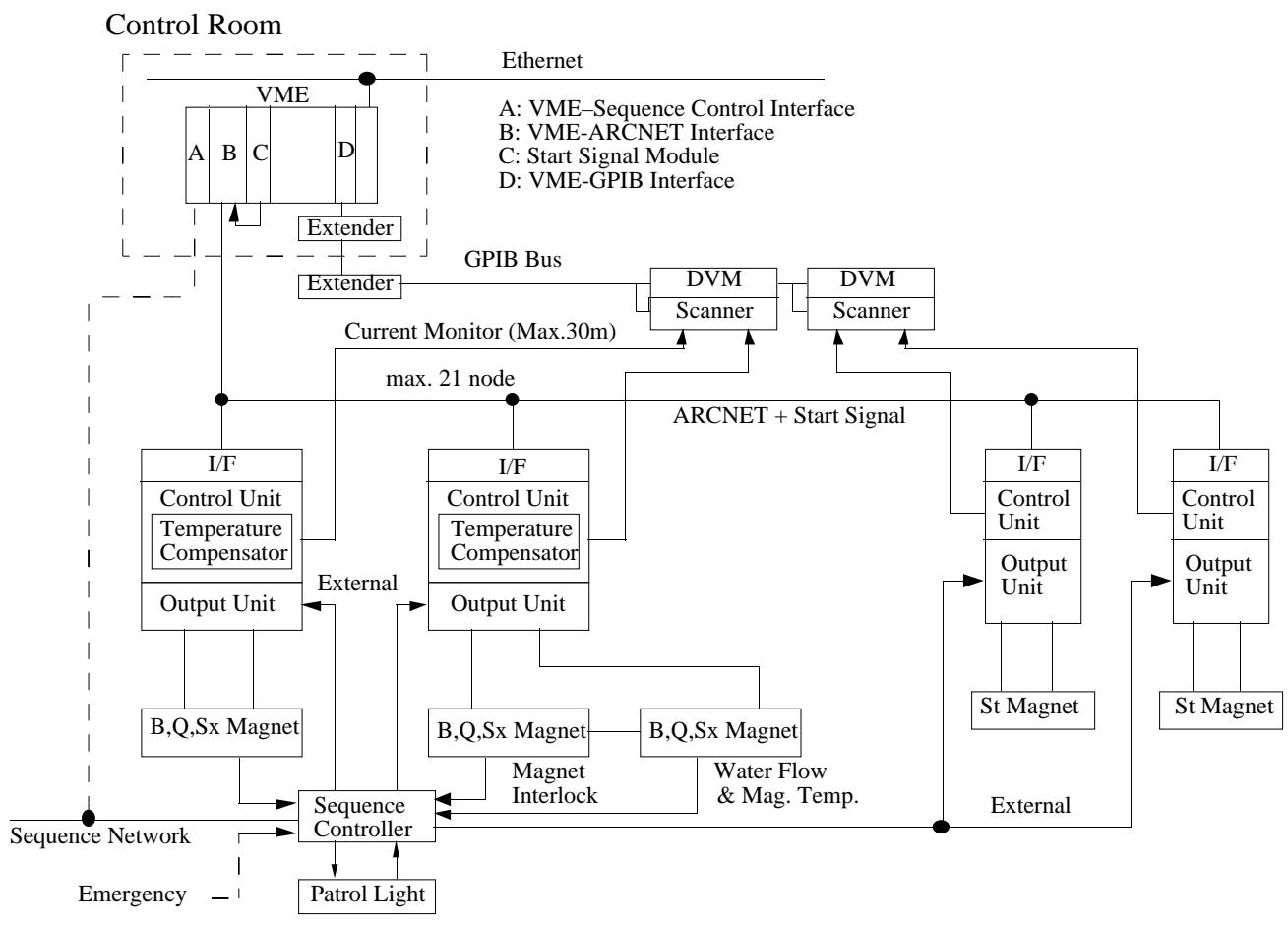

Figure: 1 Control System for Magnet Power Supply

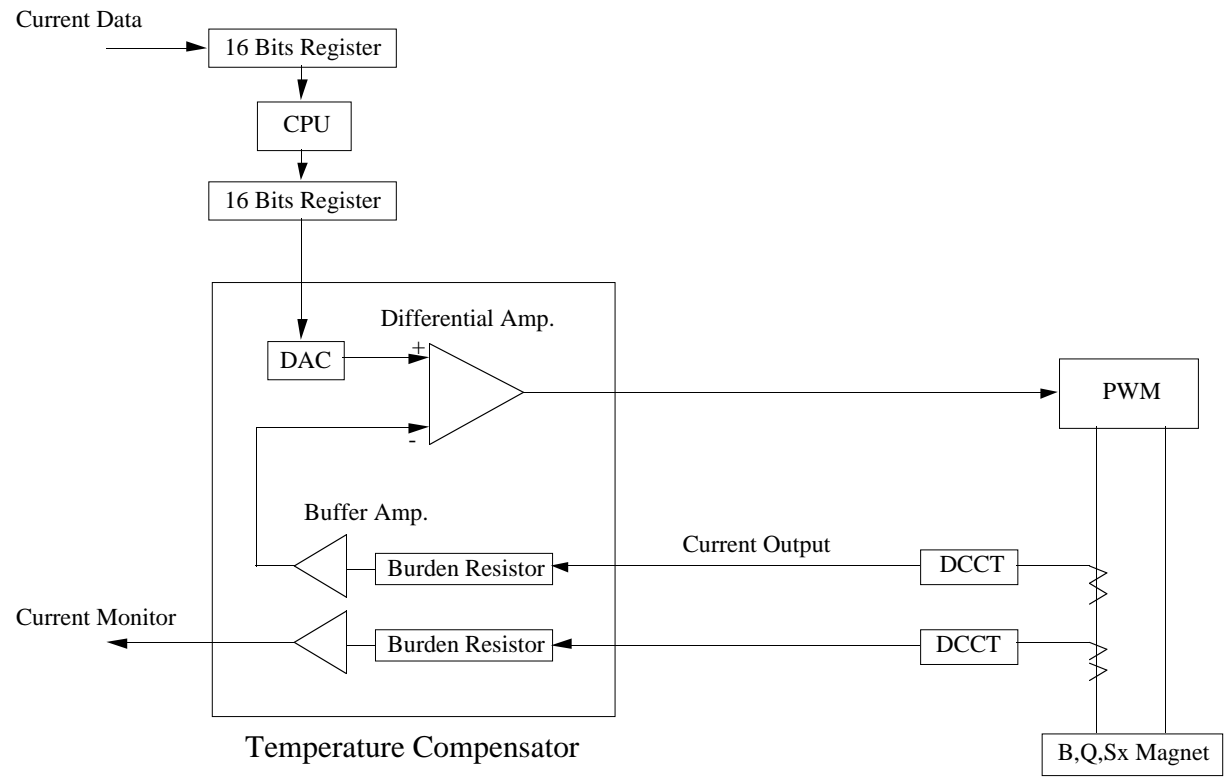

Figure: 2 Temperature Compensator for B and Q Magnet Power Supplies 